\title{
Blindness after cardiac arrest
}

\author{
A. H. SABAH \\ M.A., M.B., M.R.C.P. \\ Cardiothoracic Department, \\ Central Middlesex Hospital, London, N.W.10
}

\section{Summary}

Three cases of isolated blindness after cardiac arrest are described.

Blindness was associated with normal pupillary light reflexes and no observable changes in the fundi, features identifying it as cortical.

Possible mechanisms have been discussed. It is suggested that this complication is more common than has been reported in the literature.

\section{Introduction}

Neuropsychiatric disorders, including blindness, may be an expression of cerebral anoxia. As some degree of anoxia occurs during cardiac arrest, it is surprising that only nineteen cases of blindness following cardiac resuscitation have been described in the English literature since 1940 (Table 1). Three further cases are reported.

TABLE 1

Type of blindness and neurological manifestations

\begin{tabular}{|c|c|c|c|c|c|c|}
\hline \multirow[b]{2}{*}{ Reference } & \multicolumn{4}{|c|}{ Type of blindness } & \multicolumn{2}{|c|}{$\begin{array}{l}\text { Other neurological } \\
\text { manifestations }\end{array}$} \\
\hline & Cortical & Retinal & $\begin{array}{l}\text { Psycho- } \\
\text { logical }\end{array}$ & $\begin{array}{l}\text { Undeter- } \\
\text { mined }\end{array}$ & Present & Absent \\
\hline Lampson, Schaeffer \& Lincoln (1948) & & & & + & + & \\
\hline Barker (1949) & & & & $\begin{array}{l}+ \\
+\end{array}$ & $\begin{array}{l}\text { NR } \\
\text { NR }\end{array}$ & $\begin{array}{l}\text { NR } \\
\text { NR }\end{array}$ \\
\hline Fox (1949) & + & & & & + & \\
\hline Behrman (1951) & + & & & & + & \\
\hline Hanks \& Papper (1951) & & $?+$ & & & + & \\
\hline Roberts, Schnabel \& Ravdin (1954) & & & & + & NR & NR \\
\hline Ginver (1954) & + & & & & + & \\
\hline Allison (1956) & + & + & & & $\begin{array}{l}+ \\
+\end{array}$ & \\
\hline Martin \& Tarrow (1956) & & & + & & NR & NR \\
\hline Blair, Irvine \& Taylor (1958) & & + & & & + & \\
\hline Hoyt \& Walsh (1958) & + & & & & + & \\
\hline Williams \& Spencer (1958) & + & & & & + & \\
\hline Kouwenhoven, Jude \& Knickerbocker (1960) & & & & + & + & \\
\hline Weinberger, Van der Woude \& Maier (1962) & $\begin{array}{l}+ \\
+ \\
+\end{array}$ & & & & $\begin{array}{l}+ \\
+\end{array}$ & $? ?+$ \\
\hline McAuley (1964) & + & & & & & + \\
\hline Present paper & $\begin{array}{l}+ \\
+ \\
+\end{array}$ & & & & $+^{*}$ & $\begin{array}{l}+ \\
+\end{array}$ \\
\hline
\end{tabular}

NR, Not reported; ?, probably; ??, neurological signs soon after the arrest were not reported, but none were present 16 days later.

*He had gastro-intestinal upset but no other localizing signs. 


\section{Case 1}

A 64-year-old man was admitted to Central Middlesex Hospital on 4 March 1966 after sustaining a posterior myocardial infarction $4 \mathrm{hr}$ previously. His blood pressure was $90 / 60 \mathrm{mmHg}$ when first seen at home, rising to $110 / 75 \mathrm{mmHg}$ in $90 \mathrm{~min}$.

On admission, examination revealed that he had a regular pulse of $90 / \mathrm{min}$, a blood pressure of $150 / 100 \mathrm{mmHg}$ and mild left ventricular failure, but no other abnormality. Three hours after admission, he developed ventricular tachycardia. Cardioversion was attempted under light general anaesthesia (thiopentone), but he developed ventricular fibrillation. This was treated by external cardiac massage, and sinus rhythm was restored after $25 \mathrm{~min}$. Though his peripheral pulses were present, his blood pressure was initially low, gradually rising to $120 /$ $100 \mathrm{mmHg}$ within $2 \mathrm{hr}$. At this stage bilateral blindness was noted. His visual acuity was limited to perception of light, pupillary light reflexes were normal, and the fundi showed no change. A superficial neurological examination revealed no other abnormality. Two days later he died from progressive pulmonary oedema without regaining his sight.

Necropsy revealed fresh occlusion of the right coronary artery, slightly enlarged left ventricle, pulmonary oedema, extensive atheroma of the abdominal aorta, and normal kidneys. The brain, arteries in the neck and the eyes were not examined.

\section{Case 2}

A 48-year-old man was admitted to Central Middlesex Hospital on 17 July 1967 after sustaining an anterior myocardial infarct $2 \mathrm{hr}$ previously. While being examined he had a cardiac arrest. ECG showed ventricular fibrillation, and external cardiac massage was started. The first attempt at D.C. defibrillation was unsuccessful. A second D.C. shock following intravenous administration of sodium bicarbonate produced supraventricular tachycardia. This was followed immediately by return of good peripheral pulses, spontaneous respiration and recovery of consciousness. The total duration of circulatory arrest was less than $10 \mathrm{~min}$. After a further synchronized D.C. shock without anaethesia, sinus rhythm was restored. His systolic blood pressure was $85 \mathrm{mmHg}$ rising to $140 / 100 \mathrm{mmHg}$ within $1 \mathrm{hr}$. At this stage he complained of dimness of vision, inability to recognize faces beyond the foot of the bed, and seeing objects in 'black and white'. His pupils reacted to light, the fundi were normal, and a superficial neurological ex- amination revealed no abnormality. Four hours later, there was some recovery of central vision, and by the following day vision was back to normal. During this time he developed bilateral subconjunctival haemorrhages, but repeated examination of the fundi showed no abnormality. Three weeks after his cardiac arrest, a detailed ophthalmological examination (Mr H. Jackson) revealed that his visual acuity, visual fields (tested on a perimeter) and fundi were all normal. A full neurological examination and an EEG were also normal.

\section{Case 3}

A 58-year-old man presented on 26 December 1967 with severe left ventricular failure after sustaining a myocardial infarct $18 \mathrm{hr}$ before admission. He had a history of myocardial infarction followed by angina 11 years previously. His systolic blood pressure was $90 \mathrm{mmHg}$ rising to $160 / 90 \mathrm{mmHg}$ in $12 \mathrm{hr}$; a single blood pressure reading in 1960 was $210 / 100 \mathrm{mmHg}$.

On the 4th day after admission he developed ventricular fibrillation. The first attempt at D.C. defibrillation was only temporarily successful. A second D.C. shock following intravenous administration of sodium bicarbonate and lignocaine restored sinus rhythm. However, his blood pres sure remained unrecordable until a single doseco of $10 \mathrm{mg}$ of metaraminol raised it to $90 / 60 \mathrm{mmHg}$. The total duration of the circulatory arrest was less than $20 \mathrm{~min}$.

He regained consciousness but was noisy and confused. Forty minutes after the onset of the cardiac arrest he complained of being blind. His visual acuity was limited to perception of light. The pupillary light reflexes and the fundi were normal, and a neurological examination revealed no other abnormality. An hour later his blood pressure was $180 / 80 \mathrm{mmHg}$. He was able to count fingers at $2 \mathrm{yd}$, and distinguish the colours yellow, red and white, but both green and blue were called black. During this period he had severe nausea, retching and diarrhoea, passing six watery stools in $3 \mathrm{hr}$. The acute gastro-intestinal upset ended as abruptly as it started, $3 \mathrm{hr}$ after his arrest.

By the following morning he was orientated, his visual acuity was normal and he had no further gastro-intestinal symptoms.

\section{Discussion}

Cortical blindness, from any cause, is characterized by complete loss or gross impairment of vision, with normal pupillary light reflex and normal fundi. Hysteria is excluded by the absence of reflex blinking to menace. Spatial 
disorientation, visual agnosia, loss of colour vision, denial of blindness and visual hallucinations may occur with cortical blindness, but are not a constant feature of this syndrome (Symonds \& MacKenzie, 1957). The presence of an abnormal EEG gives further support to the diagnosis (Kooi \& Sharbrough, 1966). Loss of vision from occipital-cortex infarcation is permanent in a quarter of the cases (Symonds \& MacKenzie, 1957). If recovery occurs, it is slow to start and may be incomplete, with central vision recovering first, and perception of motion may return before perception of a stationary object (Hoyt \& Walsh, 1958).

In the cases reported here, although there was gross loss of vision, the pupillary light reflexes were normal and there was no observable change in the fundi; features identifying the blindness as cortical. The first patient, who had the more marked loss of vision and the more prolonged hypotension, did not survive long enough to allow further observation of the development or resolution of the lesion. The second and third patients had gross visual disturbance, but this was transient, probably because the circulatory arrest and the subsequent hypotension were not prolonged. Metaraminol was given to the third patient only. In two of the documented cases of cortical blindness following cardiac arrest recovery started 5 and 6 weeks, respectively, after the arrest (Hoyt \& Walsh, 1958 ; McAuley, 1964). This delay is probably related to the severity of anoxic cortical damage inflicted during the circulatory arrest and the subsequent hypotension.

Visual disturbance after cardiac arrest is probably more common than has been reported. The resuscitated patient, who may be confused or sedated, may deny, not complain of or not live long enough to notice, his loss of vision. Since our attention was drawn to this possibility by the first case, we have been looking carefully for it, but have only identified it twice in seventeen subsequent successful resuscitations.

Blindness in the three cases described is probably due to cerebral anoxia. They are unusual because blindness was not accompanied by other neurological signs (although the third patient developed transient gastro-intestinal upset which may have been due to brain damage). Although in hypoxic hypoxia the globus pallidus, the subthalamic nuclei and the dentate nucleus are the more severely affected, in cardiac arrest with circulatory stagnation in addition to hypoxaemia, the cerebral and cerebellar cortex are more susceptible. This may be because in circulatory failure essential nutrients beside oxygen do not reach the cortex (McMenemey, 1966). The susceptibility of the cortex in the calcarine fissure to hypoxic damage may also be affected by the vascular anatomy, as this part of the brain receives its blood supply from both the middle and posterior cerebral arteries. Although this dual blood supply tends to lessen the extent of ischaemic damage when only one vessel is occluded, it does not protect this area from damage when there is general hypoxia, and may increase the liability to serious injury when hypotension is prolonged (McMenemey, 1966). Indeed, occipital lobe infarction has been described after cardiac arrest (Robinson, Torro \& Scatcliffe, 1966).

Blindness after cardiac arrest may also result from retinal damage (Allison, 1956; Martin \& Tarrow, 1956). Changes in the fundi occur in this condition, papilloedema being the most striking feature. In the case described by Hanks \& Papper (1951), blindness followed massive post-operative haemorrhage and cardiac arrest. Although these authors did not comment on the appearance of the fundi, the presence of complete blindness with loss of pupillary light-reflex suggests that the blindness may have been retinal in origin. The part played by the bleeding and by the arrest in its pathogenesis is not easy to separate, since this type of blindness can also follow acute blood loss without cardiac arrest (Pears \& Pickering, 1960).

Factors other than systemic hypotension may also be involved in causing retinal damage, since this type of blindness is known to have developed 5 min after the blood pressure was reduced from $270 / 160$ to $180 / 110 \mathrm{mmHg}$ by intramuscular hexamethonium (Bruce, 1955). Goldsmith \& Hewer (1952) attributed blindness developing after general anaesthesia and controlled hypotension to retinal artery spasm, rather than hypotension. The retinal artery blood pressure corresponding to the amaurotic threshold varies between 7 and $25 \mathrm{mmHg}$. Even at a retinal pressure of $7 \mathrm{mmHg}$ (which corresponds to a brachial artery pressure of well below $50 \mathrm{mmHg}$ ) the retinal ganglion and bipolar cells remain viable though temporarily functionless (Goldsmith \& Hewer, 1952). In their case, unilateral blindness developed in a normotensive patient, though the brachial pressure did not fall below $70 / 50 \mathrm{mmHg}$.

Fundal changes, without visual damage, have been described after recovery from complete circulatory arrest during cardiac surgery under profound hypothermia (Lamb, 1961). Transudates occurred in four out of fifteen patients and haemorrhages in one. Similar asymptomatic changes occurring after acute blood loss 
have been attributed to hypotension (Pears \& Pickering, 1960). The relevance of these observations to blindness after cardiac arrest is not apparent.

Blindness after cardiac arrest may occur as an isolated phenomenon, as in the two cases described, or more commonly, as a part of neurological deficit (see Table 1). It is surprising that blindness due to isolated retinal damage has not been reported. Out of twenty-one cases, blindness was cortical in twelve, retinal in two (or possibly three), psychological in one, and undetermined in five. The duration of the circulatory arrest and the subsequent hypotension is an important aetiological factor in cortical blindness, while retinal artery spasm may also be important in blindness due to retinal damage.

\section{Acknowledgments}

I would like to thank Dr M. McNicol for allowing me to report his patients, and for his criticism and advice; $\mathbf{M r} \mathbf{H}$. Jackson for his criticism; and the staff of the Cardiothoracic Department for their encouragement.

\section{References}

Allison, R.S. (1956) Discussion of the clinical consequences of cerebral anoxia. Proc. roy. Soc. Med. 49, 609.

BARKer, A.B. (1949) quoted by Loken, A.C., Haymaker, W. \& Paulson, D.L. (1949) Stab wound of the heart followed by temporary cession of heart beat with resuscitation by cardiac massage. Surgery, 26, 745.

BeHRMAN, S. (1951) Amaurosis fugax et amaurosis fulminans. Arch. Ophthal. 45, 458.

BlaIR, D.W., IRVINE, W.T. \& TAYLOR, R.C. (1958) Recovery from neurological sequelae after cardiac arrest. Brit. med. J. i, 1951.

Bruce, G.M. (1955) Permanent bilateral blindness following the use of hexamethonium chloride. Arch. Ophthal. 54, 422.

Fox, J.C. (1949) Restoration of cerebral function after prolonged cardiac arrest. J. Neurosurg. 6, 361.
Ginver, I. (1954) Visual loss following cardiac arrest. Arch. Ophthal. 51, 878.

Goldsmith, A.J.B. \& Hewer, A.J.H. (1952) Unilateral amaurosis with partial recovery after using hexamathonium iodide. Brit. med. J. ii, 759.

Hanks, E.C. \& PAPPER, E.M. (1951) Cardiac resuscitation. N.Y. St. J. Med. 51, 1801.

HoYT, W.F. \& Walsh, F.B. (1958) Cortical blindness with partial recovery following acute cerebral anoxia from cardiac arrest. Arch. Ophthal. 60, 1061.

KooI, K.A. \& Sharbrough, F.W., III, (1966) Electrophysiological findings in cortical blindness, report of a case. Electroenceph. clin. Neurophysiol. 20, 260.

KouWenhoven, W.B., Jude, J.R. \& KNICKeRBocker, G.G. (1960) Closed chest cardiac massage. J. Amer. med. Ass. 173, 1064.

LAMB, A. (1961) Ocular changes occurring during cardiac surgery under profound hypothermia and occlusion. Brit. J. Ophthal. 45, 490.

LAMPSON, R.S., Schaeffer, W.C. \& Lincoln, J.R. (1948) Acute circulatory arrest from ventricular fibrillation for twenty-seven minutes with complete recovery. J. Amer. med. Ass. 137, 1575.

Martin, J. T. \& TARrow, A.B. (1956) A review of cardiac resuscitation. Curr. Res. Anesth. 35, 147.

McAuley, F.D. (1964) Prolonged visual failure following cardiac arrest due to accidental hypothermia. Brit. J. Ophthal. 48, 628.

McMenemey, W.H. (1966) Systematic Pathology (Ed. by G. Payling Wright and W. St C. Symmers), 1st edn, Vol. 2, p. 1159. Longmans, London.

Pears, M.A. \& PiCkering, G.W. (1960) Changes in the fundus oculi after haemorrhage. Quart. J. Med. 29, 153.

Roberts, B., SChNabel, T.G. \& Ravdin, I.S. (1954) Multiple episodes of cardiac arrest, report of a case. J. Amer. med Ass. 154, 581.

Robinson, F., Torro, R.S. \& Scatliff, J.H. (1966) Angiographic recognition of occipital lobe infarction. Neurology (Minneap.), 16, 1016.

Symonds, C. \& MACKenzie, I. (1957) Bilateral loss of vision from cerebral infarction. Brain, 80, 415.

Weinberger, H.A., VAN DeR Woude, R. \& Maier, H.C. (1962) Prognosis of cortical blindness following cardiac arrest in children. J. Amer. med. Ass. 179, 126.

Williams, G.R. \& SPENCER, F.C. (1958) Clinical use of hypothermia following cardiac arrest. Ann. Surg. 148, 462. 